\title{
Influência da pré-saturação do agregado miúdo reciclado na viscosidade e resistência à compressão de argamassas
}

\author{
Influence of the pre-saturation of recycled fine aggregate \\ in the viscosity and resistance to compression of mortars
}

\section{Juliana Oliveira Malta \\ Vanessa Silva Silveira \\ Jardel Pereira Gonçalves \\ Romildo Dias Toledo Filho}

Juliana Oliveira Malta Instituto Federal de Educação, Ciência e Tecnologia de Sergipe Aracaju - SE - Brasil

Vanessa Silva Silveira Universidade Federal da Bahia Salvador - BA - Brasil

Jardel Pereira Gonçalves Universidade Federal da Bahia Salvador - BA - Brasil

Romildo Dias Toledo Filho Programa de Engenharia Civil Universidade Federal do Rio de

Janeiro

Rio de Janeiro - RJ - Brasil

Recebido em 20/02/13

Aceito em 22/10/13

\section{Resumo}

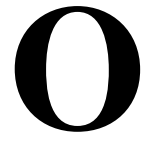

$\mathrm{s}$ diferentes tratamentos dados aos agregados reciclados influenciam nas propriedades das argamassas nos estados fresco e endurecido. Como esses agregados possuem características diferentes das dos agregados naturais, tais como elevada absorção, forma lamelar, textura áspera e menor massa específica, há necessidade de estudar os diferentes procedimentos empregados na dosagem de misturas contendo esses resíduos e a influência deles no comportamento físico e mecânico das argamassas. Dois procedimentos foram utilizados no presente estudo: compensação de parte da água absorvida pelos agregados miúdos reciclados (AMR), fazendo-se sua présaturação, e uso dos agregados secos em estufa. Este trabalho tem como objetivo principal avaliar a influência desses procedimentos de dosagem nas propriedades reológicas, teor de água quimicamente combinada e resistência à compressão de argamassas contendo $25 \%$ e $50 \%$ de agregados reciclados em substituição (em massa) aos agregados naturais. Os resultados mostram que a pré-saturação influencia as propriedades das argamassas no estado fresco e endurecido. A presença do AMR promove misturas com maior viscosidade, maior teor de água livre e menor resistência à compressão.

Palavras-chave: Argamassa. Dosagem. Agregado miúdo reciclado.

\section{Abstract}

The different treatments given to recycled aggregates influence the properties of mortars in fresh and hardened states. As these aggregates have characteristics different from those of natural aggregates, such as high absorption, lamellar form, rough texture and lower density, there is a need to study the different procedures used in the dosage of mixtures containing these residues and their influence on the physical and mechanical behavior of mortars. Two procedures were used in this study: partial compensation of the water absorbed by the recycled fine aggregates (RFA) through their pre-saturation and use of aggregates dried in an oven. The main aim of this study is to evaluate the influence of these dosage procedures on the viscosity, chemically combined water content and compressive strength of mortars containing $25 \%$ and $50 \%$ of recycled aggregates replacing (by mass) natural aggregates. The results showed that the pre-saturation procedure influences the properties of the mortars in the fresh and hardened states. The presence of the RFA promotes mixtures with higher viscosity, higher content of free water and less resistance to compression.

Keywords: Mortar. Mixture design. Recycled fine Aggregate

MALTA, J. O.; SILVEIRA, V. S.; GONÇALVES, J. P.; TOLEDO FILHO, R. D. Influência da pré-saturação do agregado miúdo 85 reciclado na viscosidade e resistência à compressão de argamassas. Ambiente Construído, Porto Alegre, v. 14, n. 1, p. 85-98, jan./mar. 2014.

ISSN 1678-8621 Associação Nacional de Tecnologia do Ambiente Construído. 


\section{Introdução}

A indústria da construção civil causa diversos impactos ao meio ambiente, devido ao grande consumo de recursos naturais, energia e geração de grandes volumes de resíduos de construção e demolição (RCD). Para minimizar tais impactos, esse importante setor da economia tem buscado otimizar os processos construtivos e utilizado tecnologias racionalizadas e sustentáveis. Apesar disso, quantidades expressivas de resíduos ainda são geradas, e o beneficiamento deles, transformando-os em novos produtos, é de grande importância.

O tipo e o volume de agregados reciclados (AR) a ser utilizados na construção civil dependem do tipo de aplicação, e é necessário que tais agregados apresentem características compatíveis com tal. Ocorre que os resíduos de construção são específicos de cada obra e apresentam diferenças em cada fase da construção. Os resíduos de demolição, por sua vez, podem apresentar heterogeneidade elevada se ela não for realizada de forma seletiva. Assim, para viabilizar o uso de agregados de RCD em argamassas e concretos, estudos criteriosos precisam ser realizados, pois os agregados apresentam características peculiares, tais como (BARRA, 1996; LIMA, 1999; GONÇALVES, 2001; LEITE, 2001; GÓMEZSÓBERON, 2002; VIEIRA, 2003; PEDROZO, 2008; REIS, 2009; EVANGELISTA; BRITO, 2010; FERREIRA; BRITO; BARRA, 2011; ULSEN et al., 2013):

(a) composição definida a partir da composição do RCD (fases cerâmica, concreto, rocha e argamassa);

(b) processo de britagem (tipo de britador e classificação granulométrica), que define a granulometria do AR e o teor de finos;

(c) elevada porosidade e absorção;

(d) forma lamelar e textura mais áspera; e

(e) menor massa específica em relação aos agregados convencionais.

A variabilidade do RCD dificulta o desenvolvimento de métodos e modelos capazes de controlar e predizer as propriedades dos agregados reciclados e sua influência nas propriedades físicas, químicas e mecânicas dos materiais cimentíceos. Por exemplo, agregados reciclados de alta porosidade interferem na quantidade de água das misturas, o que pode afetar não apenas a reologia das misturas, mas também sua hidratação e propriedades no estado endurecido.

Devido a sua elevada porosidade, parte da água de amassamento utilizada na mistura é absorvida pelos grãos e não há um controle preciso da água livre e da água quimicamente combinada da matriz.

Estudos desenvolvidos por Barra et al. (2006) e Ferreira, Brito e Barra (2011) mostram que o teor de umidade e a absorção efetiva dos agregados reciclados influenciam as propriedades dos materiais cimentíceos. A influência da absorção do AR nas propriedades dos materiais cimentíceos indica que há variação da relação água/cimento da matriz, e, consequentemente, a lei de Abrams não apresenta aplicação efetiva.

Visando à aplicação tecnológica dos agregados reciclados, alguns pesquisadores definem dois procedimentos principais de dosagem, quais sejam:

(a) compensação de água (compensação total ou parcial da água absorvida pelo agregado reciclado); e

(b) sem compensação (agregado seco em estufa ou ao ar).

A compensação pode ocorrer adicionando-se parte da água absorvida pelo agregado à água de amassamento ou realizando-se a pré-saturação do AR. A quantidade de água a ser compensada é determinada a partir de ensaios de absorção de água no agregado reciclado (LEITE, 2001; REIS, 2009). Alguns autores, em seus trabalhos, compensam parte da água de absorção do AR; por exemplo, Leite (2001), Vieira (2003) e Evangelista e Brito (2010) compensam 50\% da taxa de absorção total do AR; Carrijo (2005) e Ângulo (2005) compensam $70 \%$ e Etxeberria et al. (2007) compensam $80 \%$. Outros fazem a pré-saturação (LEVY, 2001; VASQUEZ et al., 2006; MALTA, 2012) e outros, ainda, usam o AR seco em estufa ou seco ao ar (MACHADO JÚNIOR; AGNESINI; BALLISTA, 2000; PEDROZO, 2008).

Existem vantagens e desvantagens no processo de compensação. Por exemplo, embora a plasticidade das misturas seja melhorada com a compensação, não se pode garantir que a relação a/c teórica seja igual à relação $\mathrm{a} / \mathrm{c}$ efetiva da mistura. No caso da pré-saturação do AR, ainda há a possibilidade de a água migrar para a matriz, influenciando a zona de transição pasta/agregado e a quantidade de água que pode reagir com o cimento (hidratação retardada do cimento). No caso do uso do AR seco, ocorrerá, durante o processo de mistura, absorção da água de amassamento pelos agregados, diminuindo a relação $\mathrm{a} / \mathrm{c}$ teórica $\mathrm{e}$, assim, influenciando a relação água/cimento efetiva da matriz. Assim, pode-se dizer que os

86 Malta, J. O.; Silveira, V. S.; Gonçalves, J. P.; Toledo Filho, R. D. 
diferentes procedimentos utilizados resultam em misturas com relação água/cimento efetiva diferente e, consequentemente, com propriedades diferentes das inicialmente estabelecidas na dosagem.

O presente trabalho avalia, então, a influência das diferentes práticas de dosagem nas propriedades de argamassas contendo agregado miúdo reciclado (AMR). A viscosidade, a resistência à compressão e o teor de água quimicamente combinada de argamassas contendo agregados miúdos présaturados e secos em estufa são comparados com os da mistura de referência sem AMR.

\section{Materiais e métodos}

\section{Materiais}

O RCD utilizado no trabalho foi proveniente do canteiro de obra de uma construtora da cidade de Salvador. O empreendimento correspondia à construção de um condomínio residencial composto de duas torres, com estrutura de concreto armado e alvenaria em blocos cerâmicos. O Programa de Gerenciamento de Resíduos da Construção Civil possuía boas práticas de coleta, acondicionamento, segregação e destinação dos resíduos.

A coleta e a segregação dos resíduos ocorreram no próprio canteiro de obras nas baias dos resíduos Classe A. Os resíduos de construção foram separados manualmente, visando determinar sua composição gravimétrica nas frações argamassa, concreto, alvenaria e outros (denomina-se como "outros" os resíduos contendo mais de um tipo de resíduo, como, por exemplo, pedaços de blocos cerâmicos com argamassa aderida em sua superfície). A composição gravimétrica do RCD utilizado é apresentada na Figura 1(a). Observando-se a Figura 1 verifica-se a presença de $49 \%$ de resíduo cerâmico, $34 \%$ de argamassa, $13 \%$ de concreto e $4 \%$ de "outros". A maior fração da fase cerâmica no RCD ocorreu porque a coleta aconteceu quando a obra estava na fase de elevação da alvenaria de blocos cerâmicos.

A Figura 1(b) mostra a curva granulométrica do agregado miúdo reciclado (AMR) e do agregado miúdo natural (AMN). Verifica-se que a curva granulométrica do AMR se encontra dentro dos limites da zona ótima inferior e superior (esses limites são encontrados na Tabela 2 - Limites da distribuição granulométrica do agregado miúdo da NBR 7211 (ABNT, 2009a)). Além disso, o AMR apresenta distribuição granulométrica melhor do que o agregado natural, ou seja, mais contínua, favorecendo o empacotamento das misturas.

A britagem do resíduo ocorreu em circuito aberto, num britador de martelo disponível no próprio canteiro de obras. Após, a britagem o resíduo passou por um processo de classificação granulométrica, sendo utilizada a fração passante na peneira de abertura $4,75 \mathrm{~mm}$.

Para os ensaios com agregados reciclados, foram utilizados os mesmos procedimentos normalizados para agregados convencionais, com exceção do ensaio de absorção, que foi realizado segundo o método proposto por Leite (2001) e adaptado por Reis (2009). Para esses ensaios não foram realizadas repetições.

Nesse método a amostra é seca em estufa por $24 \mathrm{~h}$, resfriada à temperatura ambiente e, a seguir, é colocada na peneira e presa no aparato da balança hidrostática. Em seguida, a água é gradualmente adicionada com o auxílio de uma mangueira, sem agitação do recipiente, até que toda a amostra seja coberta e a lâmina d'água fique abaixo da borda da peneira. Em seguida, é monitorado o ganho de massa do agregado submerso, com leituras da massa do conjunto em tempos predeterminados. Após cada leitura, o material é agitado cuidadosamente com uma espátula, por $1 \mathrm{~min}$, para facilitar a saída de ar presente na amostra, e deixado em repouso para estabilizar até a próxima leitura.

\section{Figura 1 - (a) Composição gravimétrica do AMR e (b) curva granulométrica da areia natural e do} agregado miúdo reciclado

(a)

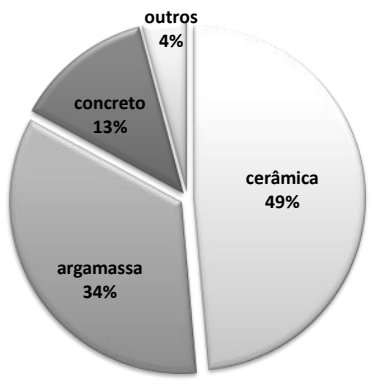

(b)

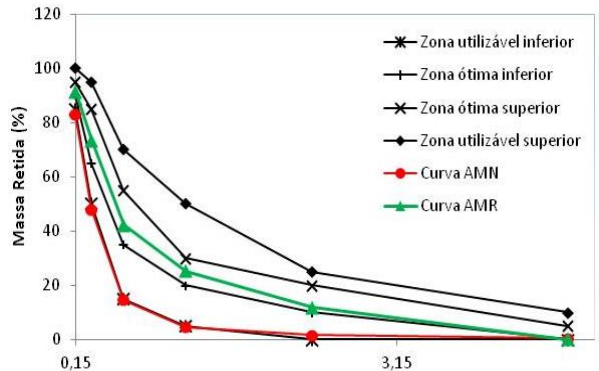

Abertura da peneira $(\log ) \cdot(\mathrm{mm})$ 
Na Tabela 1 são apresentados os resultados dos ensaios de caracterização dos agregados. Pode-se notar que o AMR apresenta maior percentual de materiais pulverulentos do que o agregado natural, devido ao processo de beneficiamento do resíduo que favorece a formação de material fino, inferior a $0,075 \mathrm{~mm}$. As massas específicas e unitárias do AMR são inferiores quando comparadas às do $\mathrm{AMN}$, o que indica que o resíduo é um material mais leve e que a quantidade a ser utilizada no traço em massa deve ser corrigida, a fim de garantir o mesmo volume a ser produzido de argamassa de referência.

Em relação às diferenças granulométricas entre o AMN e o AMR, nota-se que o AMR apresenta um módulo de finura maior do que o $\mathrm{AMN}$, indicando que o agregado natural possui uma granulometria mais fina e com menor dimensão máxima característica das partículas.

A Figura 2(a) apresenta o gráfico da absorção de água do AMR com o tempo, enquanto a Figura 2(b) mostra a variação da taxa de absorção até um tempo de $4 \mathrm{~h}$. A taxa de absorção foi calculada em relação à absorção total do agregado, que após 24 $\mathrm{h}$ de imersão foi de $16,4 \%$. Pode-se observar que a taxa de absorção é muito alta nos primeiros minutos e que após $30 \mathrm{~min}$ de contato com a água o agregado já absorve cerca de $75 \%$ da água de saturação. Como esse tempo é muito alto para o umedecimento do agregado durante uma operação de mistura, adotou-se nesta pesquisa a taxa de compensação para um tempo de $10 \mathrm{~min}$, que corresponde a um valor de 40,7\% ( 6,7\% da água necessária para a saturação do agregado).

Tabela 1 - Resultados dos ensaios de caracterização dos agregados miúdos natural e reciclado

\begin{tabular}{|c|c|c|c|}
\hline Características & Norma & AMN & AMR \\
\hline $\begin{array}{l}\text { Materiais } \\
\text { Pulverulentos }\end{array}$ & $\begin{array}{l}\text { NBR NM } 46 \\
(\mathrm{ABNT}, 2003 \mathrm{a})\end{array}$ & $4,38 \%$ & $6,09 \%$ \\
\hline Massa Específica & $\begin{array}{l}\text { NBR NM } 52 \\
(\text { ABNT, 2009b) }\end{array}$ & $2,62 \mathrm{~kg} / \mathrm{dm}^{3}$ & $2,46 \mathrm{~kg} / \mathrm{dm}^{3}$ \\
\hline Massa Unitária Solta & $\begin{array}{l}\text { NBR NM } 45 \\
(\text { ABNT, 2006) }\end{array}$ & $1,57 \mathrm{~kg} / \mathrm{dm}^{3}$ & $1,16 \mathrm{~kg} / \mathrm{dm}^{3}$ \\
\hline \multirow[b]{2}{*}{ Granulometria } & \multirow{2}{*}{$\begin{array}{l}\text { NBR NM } 248 \\
(\mathrm{ABNT}, 2003 \mathrm{~b})\end{array}$} & Módulo de finura: 1,52 & Módulo de finura: 2,44 \\
\hline & & $\begin{array}{l}\text { Dimensão máxima } \\
\text { característica: } 1,18 \mathrm{~mm}\end{array}$ & $\begin{array}{l}\text { Dimensão máxima } \\
\text { característica: } 4,75 \mathrm{~mm}\end{array}$ \\
\hline
\end{tabular}

Figura 2 - (a) Curva de absorção de água do AMR versus tempo e (b) curva da taxa de absorção de água do AMR versus tempo

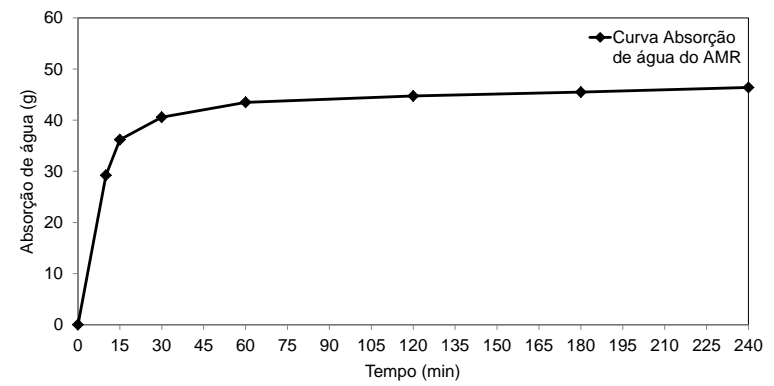

(a)

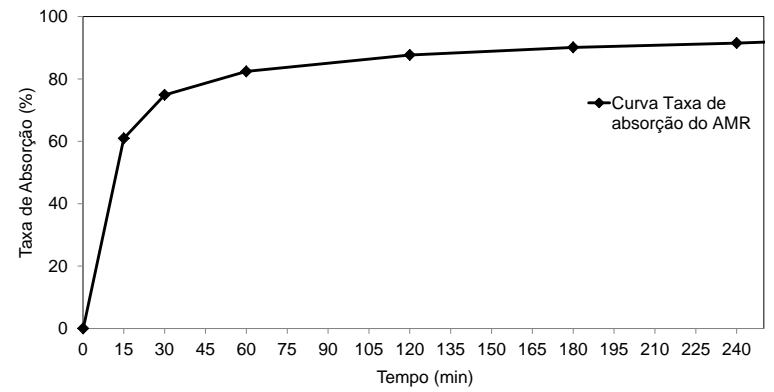

(b)

88 Malta, J. O.; Silveira, V. S.; Gonçalves, J. P.; Toledo Filho, R. D. 
A partir da micrografia, mostrada na Figura 3, verifica-se que a morfologia do grão da areia reciclada é semelhante à esférica, porém com contornos irregulares. Nota-se, também, a rugosidade e a porosidade da superfície, características que influenciam nos parâmetros de dosagem como teor de água, teor de pasta e maior dificuldade no escoamento.

A Figura 3 apresenta a micrografia do AMR realizada num microscópio eletrônico de varredura.

A superficial específica (BET) das areias foi obtida utilizando-se o equipamento Nova 1000 Quantachrome, usando nitrogênio como gás adsorvente, após preparação em vácuo a $200{ }^{\circ} \mathrm{C}$ por $3 \mathrm{~h}$. A areia reciclada apresentou uma área superficial específica de $10,1 \mathrm{~m}^{2} / \mathrm{g}$, enquanto a areia natural apresentou área BET de $4,2 \mathrm{~m}^{2} / \mathrm{g}$. Observa-se que a área específica do AMR é 2,4 vezes maior que a área da areia natural, indicando maior área de molhagem. Considerando-se as características apresentadas pela AMR, é de se esperar que as misturas com esse tipo de agregado necessitem de mais água (ou aditivos plastificantes) para reduzir a fricção entre os grãos e garantir a mesma trabalhabilidade das misturas convencionais.

Os demais materiais utilizados na produção das argamassas foram:

(a) cimento Portland de alta resistência inicial (CP V - ARI), disponível comercialmente na cidade de Salvador;

(b) água da concessionária de abastecimento local da cidade de Salvador; e

(c) aditivo superplastificante Glenium 51 (BASF).

\section{Métodos}

Neste trabalho foram desenvolvidas argamassas com proporção cimento:areia igual a 1:1,5 (em massa) e relação água/cimento $(\mathrm{a} / \mathrm{c})$ 0,4, 0,5 e 0,6. Foram produzidas argamassas de referência (somente com agregado natural) e misturas com teor de substituição, em massa, de $25 \%$ e $50 \%$ de agregado miúdo natural por AR. Para manter o mesmo volume de agregado nas misturas, a massa de AMR foi corrigida considerando-se as massas específicas do agregado reciclado $\left(2,46 \mathrm{~g} / \mathrm{cm}^{3}\right)$ e do agregado natural $\left(2,62 \mathrm{~g} / \mathrm{cm}^{3}\right)$. Foram moldados 16 corpos de prova (cps) com $5 \mathrm{~cm}$ de diâmetro e $10 \mathrm{~cm}$ de altura para cada mistura, para realização de ensaios de resistência à compressão axial nas idades de 3, 7 e 28 dias (4 cps por idade) e absorção por imersão na idade de 28 dias (4 cps).

Para as misturas contendo agregados présaturados, o percentual de compensação de água utilizado foi de $6,7 \%$ em relação à absorção total do AMR, fazendo a homogeneização. Esse procedimento era realizado $10 \mathrm{~min}$ antes da mistura dos materiais na betoneira. Todo o resíduo era colocado numa bandeja, onde era acrescentada a água de pré-saturação e feita a mistura através de movimentos circulares com espátulas ou colheres, a fim de que a mistura se tornasse homogênea.

Para as misturas com agregados secos, a única água adicionada à mistura foi a água de amassamento. Os agregados foram secos em estufa a aproximadamente $100{ }^{\circ} \mathrm{C}$ por, pelo menos, $24 \mathrm{~h}$. Posteriormente, eram retirados da estufa e cobertos com plástico para resfriamento natural e não absorção da umidade do ambiente, sendo armazenados, por fim, em bombonas com tampas.

As argamassas foram denominadas como:

(a) ARG REF: argamassas de referência, somente com agregado natural;

(b) ARG 25\%: $\operatorname{argamassas}$ com $25 \%$ de substituição do agregado miúdo natural (AMN) pelo agregado miúdo reciclado (AMR) présaturado;

(c) ARG 25\% SC: argamassas com $25 \%$ de substituição do AMN pelo AMR seco em estufa;

(d) ARG 50\%: argamassas com 50\% de substituição do AMN pelo AMR pré-saturado; e

(e) ARG 50\% SC: argamassas com 50\% de substituição do AMN pelo AMR seco em estufa.

Para manter a mesma trabalhabilidade da mistura com relação $\mathrm{a} / \mathrm{c}=0,4$ contendo $\mathrm{AMR}$, sem présaturação, foi necessário o uso de uma quantidade de aditivo plastificante de $0,06 \%$ (em relação à massa de cimento) para as misturas com $25 \%$ de AMR, e $0,1 \%$ para misturas com $50 \%$ de AMR. Pode-se notar que as quantidades utilizadas foram pequenas, porém suficientes para elevar a consistência dessas argamassas de tal forma que apresentassem condições de moldabilidade (a consistência foi verificada através do ensaio de "mesa de consistência" - NBR 7215 (ABNT, 1996)). As argamassas foram misturadas numa argamassadeira de bancada com capacidade máxima de $5 \mathrm{~L}$, também segundo o procedimento recomendado pela NBR 7215 (ABNT, 1996). 
Figura 3 - Microscopia eletrônica de varredura da areia reciclada

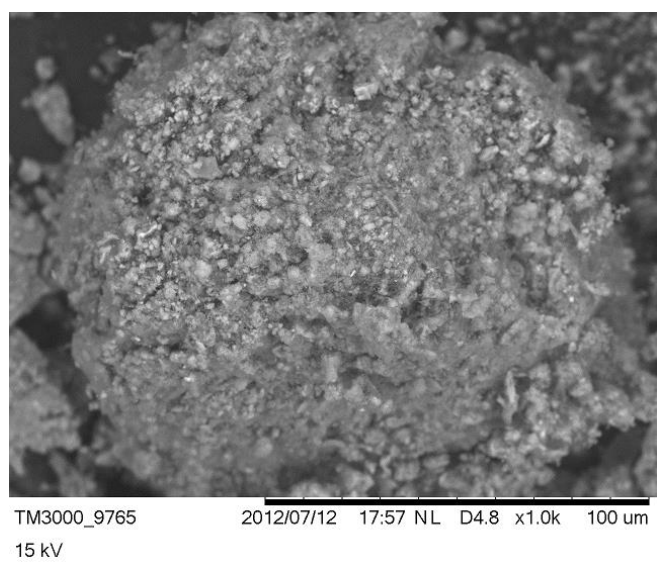

Para a análise das argamassas no estado fresco utilizou-se o reômetro Brookfield. O reômetro Brookfield possui rotação controlada, e a reologia da argamassa é medida por meio da rotação do spindle (palheta), que fica imerso no fluido. Quando o torque é aplicado ao fluido, ocorre a medida do cisalhamento resultante. Esse ensaio foi realizado no Laboratório de Estruturas e Materiais da COPPE/UFRJ, onde as 15 misturas foram reproduzidas em quantidade suficiente para as análises reológicas. Todas as amostras foram submetidas às mesmas condições de tempo médio de mistura. Na confecção dessas misturas não foi utilizado aditivo superplastificante.

A avaliação da influência do AMR na quantidade de água combinada foi realizada através de análises termogravimétricas. As análises termogravimétricas foram realizadas no equipamento SDT Q600 TA Instruments, com as seguintes condições experimentais:

(a) taxa de aquecimento constante de $10^{\circ} \mathrm{C} / \mathrm{min}$;

(b) temperatura entre 22 e $1000{ }^{\circ} \mathrm{C}$;

(c) fluxo de nitrogênio de $100 \mathrm{~mL} / \mathrm{min}$;

(d) referência de $\alpha-\mathrm{Al}_{2} \mathrm{O}_{3}$;

(e) massa de amostra de aproximadamente $10 \mathrm{mg}$; e

(f) cadinho de platina (referência e amostra).

As pastas foram mantidas em isoterma de $35{ }^{\circ} \mathrm{C}$ por $1 \mathrm{~h}$ no equipamento para a liberação da água livre conforme método sugerido por Dweck et al. (2009). As análises foram realizadas para as matérias-primas e para as argamassas na idade de 28 dias, somente para as misturas com relação a/c $=0,5$.

A identificação dos compostos formados foi feita a partir das temperaturas dos picos nas curvas de termogravimetria diferencial (DTG), obtidas a partir da curva termogravimétrica (TG). Segundo Taylor (1997), os picos típicos nas curvas DTG em uma matriz de cimento são:

(a) etringita, fase $\mathrm{AFt}\left(76^{\circ} \mathrm{C}\right.$ a $\left.84^{\circ} \mathrm{C}\right)$;

(b) silicato de cálcio hidratado, C-S-H $\left(104^{\circ} \mathrm{C}\right.$ a

$\left.140{ }^{\circ} \mathrm{C}\right)$

(c) sílico-aluminato de cálcio hidratado, $\mathrm{CASH}$

$\left(157^{\circ} \mathrm{C}\right.$ a $\left.163^{\circ} \mathrm{C}\right)$

(d) aluminato de cálcio hidratado, $\mathrm{CAH}\left(230^{\circ} \mathrm{C} \mathrm{a}\right.$ $\left.240^{\circ} \mathrm{C}\right)$;

(e) portlandita, $\mathrm{CH}\left(460{ }^{\circ} \mathrm{C} \mathrm{a} 465^{\circ} \mathrm{C}\right)$; e

(f) calcita, $\mathrm{CC}\left(620^{\circ} \mathrm{C} \mathrm{a} 645^{\circ} \mathrm{C}\right)$.

A quantificação dos produtos formados na hidratação das pastas foi realizada utilizando-se faixas de temperaturas da curva TG. Com as perdas de massa obtidas nas curvas TG foram calculadas as quantidades de água quimicamente combinada em base calcinada para cada mistura, de acordo com os procedimentos sugeridos por Gonçalves et al. (2006).

Para a análise das argamassas no estado endurecido foi realizado ensaio de resistência à compressão axial nas idades de 3, 7 e 28 dias. Quatro corpos de prova (CPS) foram ensaiados em cada idade. Esses CPS foram moldados, curados imersos em água saturada com cal até as idades do ensaio e capeados com mistura de enxofre a quente. Todas as etapas foram realizadas de acordo com a NBR 7215 (ABNT, 1996). Neste trabalho, a estatística (ANOVA para um fator) foi utilizada na análise e interpretação dos resultados de resistência à compressão, a partir do programa computacional Minitab para Windows, versão 16.

90 Malta, J. O.; Silveira, V. S.; Gonçalves, J. P.; Toledo Filho, R. D. 


\section{Apresentação e análise de resultados}

\section{Reologia no estado fresco}

A Figura 4 apresenta os resultados de viscosidade em função da velocidade para as argamassas de referência, com $25 \%$ de AMR com compensação e
$25 \%$ de AMR sem compensação para a/c $=0,4, a / c$ $=0,5 \mathrm{e}$ a/c $=0,6$ respectivamente. Já a Figura 5(a), (b) e (c) apresenta os resultados de viscosidade para as argamassas de referência, com $50 \%$ de AMR com compensação e $50 \%$ de AMR sem compensação para $\mathrm{a} / \mathrm{c}=0,4, \mathrm{a} / \mathrm{c}=0,5$ e a/c $=0,6$ respectivamente.

Figura 4 - Viscosidade Brookfield versus rotação: curvas da argamassa de referência, com 25\% AMR com compensação e $25 \%$ AMR sem compensação

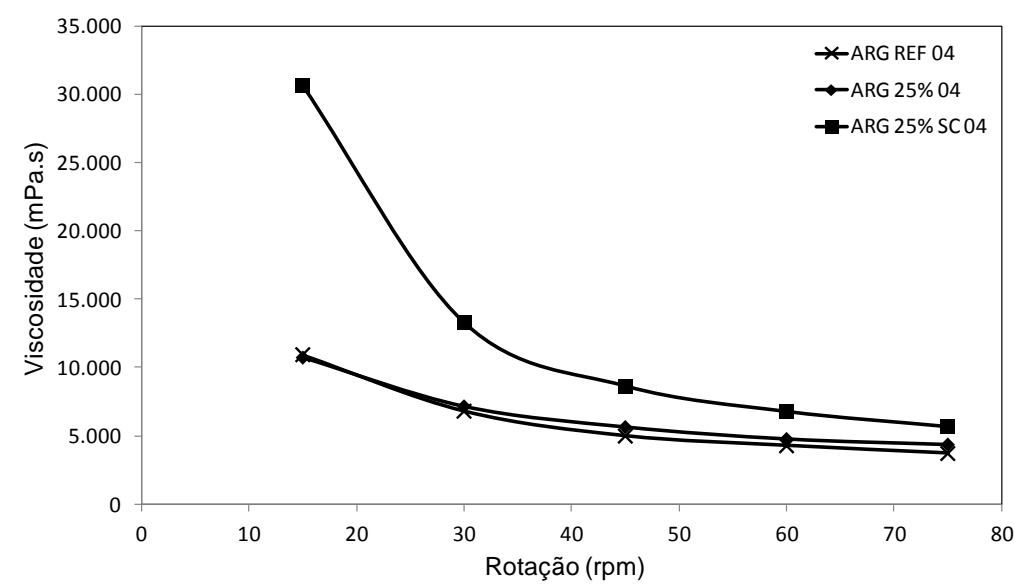

(a) $\mathrm{a} / \mathrm{c}=0,4$

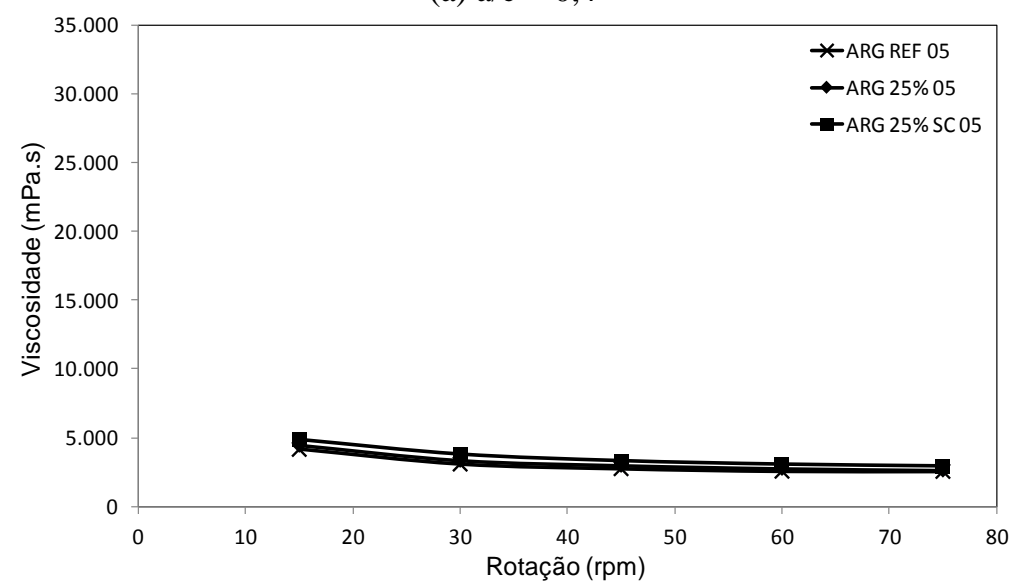

(b) $\mathrm{a} / \mathrm{c}=0,5$

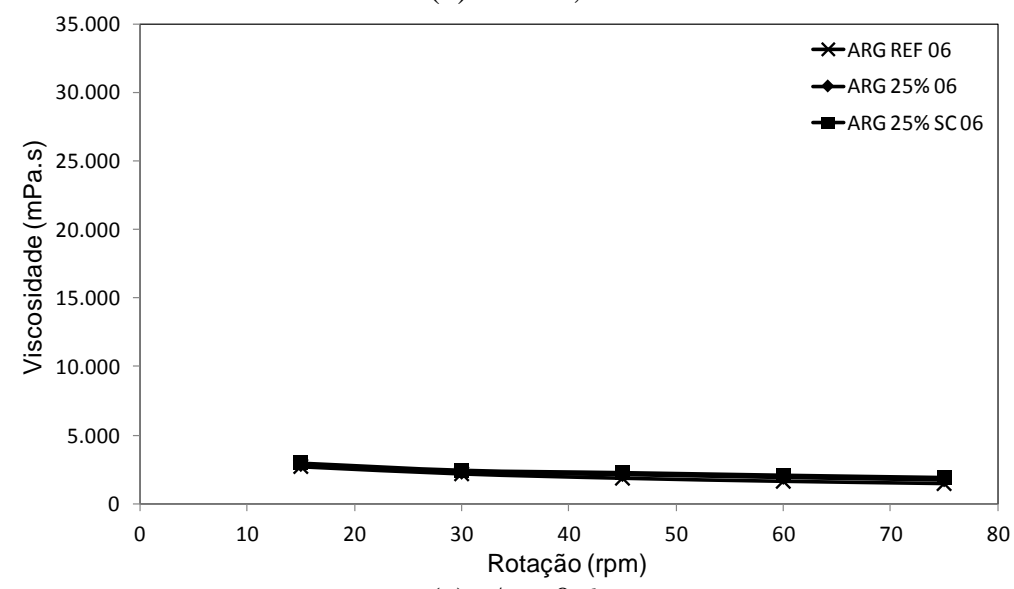

(c) $\mathrm{a} / \mathrm{c}=0,6$ 
Figura 5 - Viscosidade Brookfield versus rotação: curvas da argamassa de referência, com 50\% AMR com compensação e 50\% AMR sem compensação

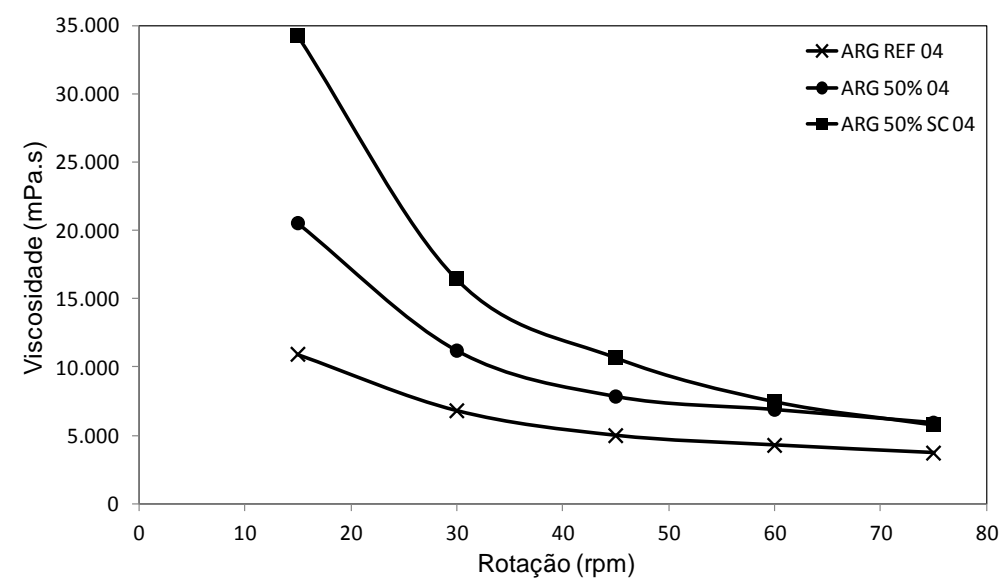

(a) $\mathrm{a} / \mathrm{c}=0,4$

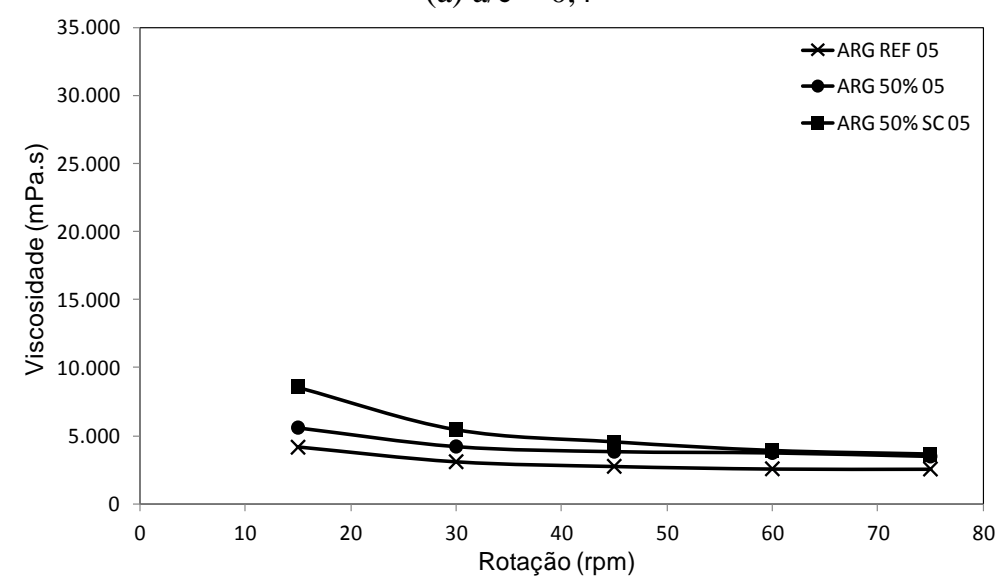

(b) $\mathrm{a} / \mathrm{c}=0,5$

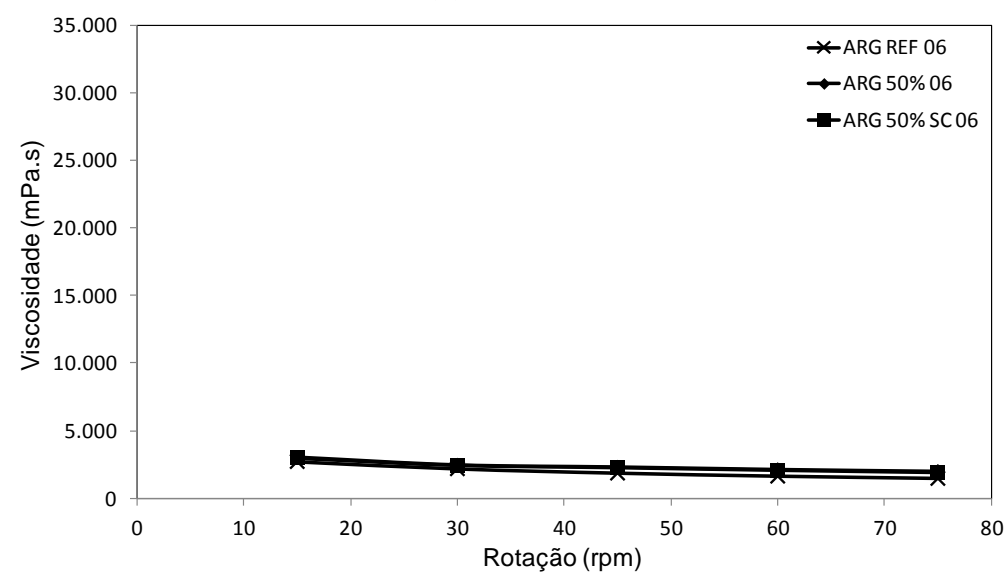

(c) $a / c=0,6$

Verifica-se que os valores de viscosidade para as argamassas com resíduo foram superiores aos das argamassas de referência para todos os fatores a/c. Esse fato pode ser atribuído à inserção do agregado reciclado, que apresenta contornos irregulares e textura mais áspera, o que aumenta a tensão de cisalhamento entre os grãos, dificultando o escoamento entre eles.
Entretanto, nota-se um afastamento maior entre as curvas para fatores a/c baixos, como é o caso de $\mathrm{a} / \mathrm{c}=0,4$. Para o teor de $25 \% \mathrm{com} \mathrm{a} / \mathrm{c}=0,5 \mathrm{e} \mathrm{a} / \mathrm{c}=$ 0,6 , as diferenças de viscosidade foram pequenas. Já para o teor de $50 \%$ com a/c $=0,5$ essa diferença aumentou, ocorrendo um discreto afastamento entre as curvas. 
Nota-se também que o processo de pré-saturação influenciou mais significativamente na viscosidade das argamassas para $\mathrm{a} / \mathrm{c}=0,4$, de tal forma que, para uma rotação de $15 \mathrm{rpm}$, o valor da viscosidade da mistura $25 \%$ SC foi três vezes maior que o valor da mistura de $25 \%$ com compensação. Para o teor de $50 \%$ de substituição, a mistura sem compensação teve sua viscosidade aumentada em $60 \%$. Esse fato indica que a água de compensação influencia as propriedades reológicas das misturas, principalmente para relações de a/c baixas. Para relações $\mathrm{a} / \mathrm{c}$ altas, como $\mathrm{a} / \mathrm{c}=0,6$, independentemente do teor de substituição, as alterações na viscosidade não foram significativas. Isso pode ser explicado porque, quando há relações $\mathrm{a} / \mathrm{c}$ maiores, existe um aumento da quantidade de água entre os grãos, ocorrendo um afastamento entre eles, o que diminui consideravelmente a fricção. Isso também explica a menor influência da incorporação do AMR na consistência dessas misturas em relação às argamassas com fatores a/c mais baixos.

Além disso, verifica-se que as maiores diferenças nos valores de viscosidade ocorrem para as menores rotações. $\mathrm{Na}$ medida em que a rotação vai aumentando, os pontos das curvas tendem a se aproximar. Verifica-se, também, que, para a menor rotação imposta (rotação inicial), ocorre o maior valor de viscosidade para todas as misturas, com maiores evidências para os fatores a/c mais baixos. Isso ocorre, provavelmente, devido à grande força inicial necessária para vencer a resistência ao giro do spindle nas misturas de argamassa. Estas se apresentam inicialmente em repouso e, quando a palheta começa a girar, detecta alto valor de viscosidade inicial, que depois tende a diminuir, quando a tendência de escoamento do fluido é criada, reduzindo a tensão cisalhante entre os grãos. Como as misturas de argamassas são diferentes, os sistemas analisados apresentaram resultados também distintos em relação aos valores de viscosidade.

\section{Análise Termogravimétrica}

$\mathrm{Na}$ Figura 6 são apresentadas as curvas das análises termogravimétricas (TG e DTG) realizadas para as misturas de argamassa. A partir dessas curvas foram calculados os parâmetros água livre, $\mathrm{RCH}^{1}$, TH e $\mathrm{OH}$, que são apresentados na Tabela 2.

Figura 6 - Curvas TG e DTG das argamassas com a/c = 0,5

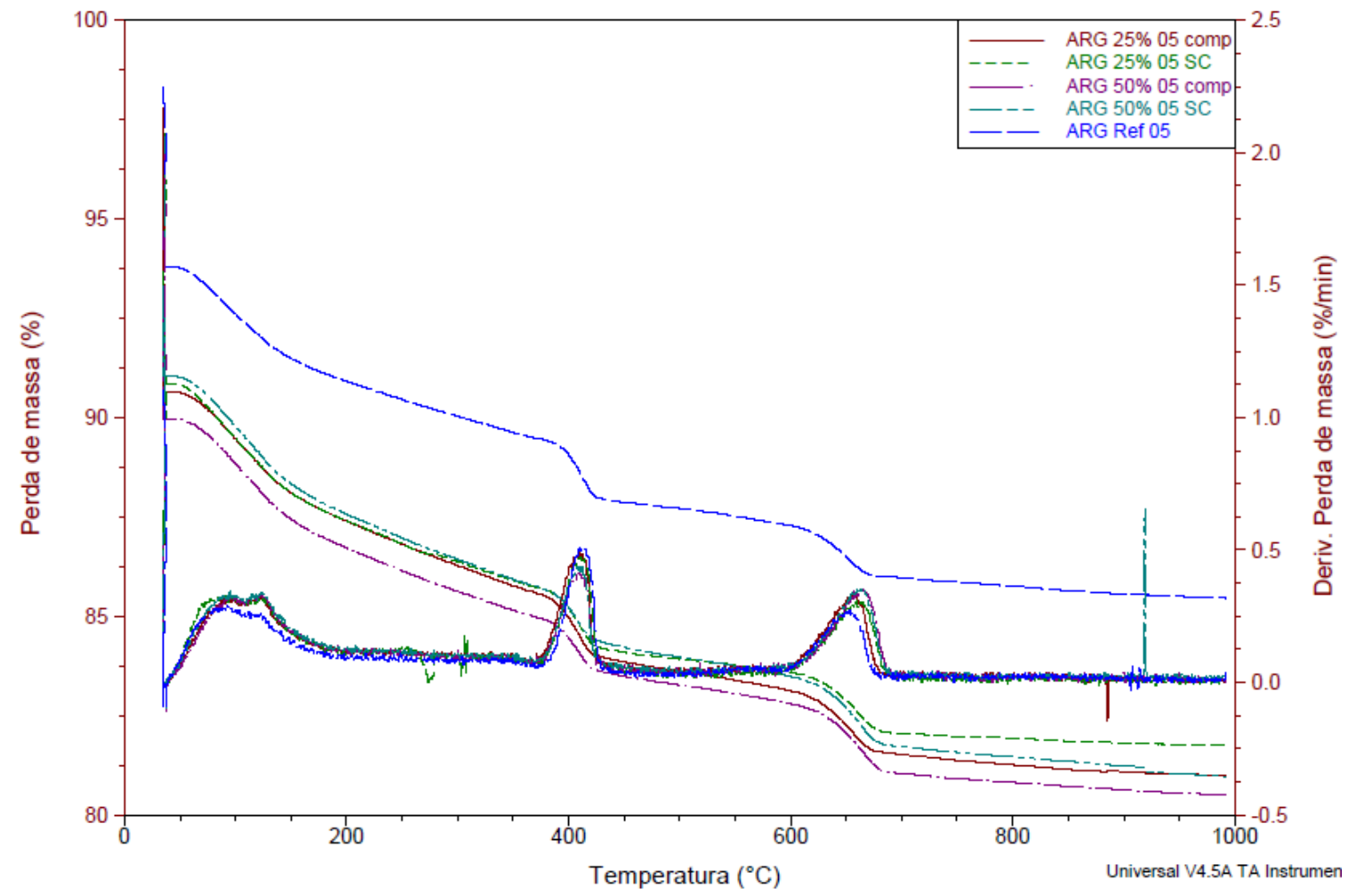

${ }^{1} \mathrm{RHC}$ : quantidade de água quimicamente combinada relativamente ao hidróxido de cálcio em relação à perda de massa a $1.000{ }^{\circ} \mathrm{C}$; TH:
quantidade de água quimicamente combinada dos hidratos entre $105^{\circ} \mathrm{C}$ e a temperatura final do pico característico ao $\mathrm{CH}$ (\%); $\mathrm{OH}$ : quantidade de água quimican
diferença entre TH e RHC. 
Tabela 2 - Parâmetros analisados para as argamassas com a/c = 0,5

\begin{tabular}{c|c|c|c|c}
\hline AMR\% & Água livre (\%) & TH (\%) & RCH (\%) & OH (\%) \\
\hline REF 05 & 2,10 & 11,38 & 1,81 & 9,56 \\
$25 \%$ 05 & 3,30 & 15,55 & 1,99 & 13,56 \\
$50 \%$ 05 & 3,39 & 16,03 & 1,73 & 14,30 \\
$50 \%$ 05 SC & 2,97 & 15,48 & 1,87 & 13,61 \\
$25 \%$ 05 SC & 3,11 & 15,36 & 1,81 & 13,54 \\
\hline
\end{tabular}

A partir dos resultados das análises termogravimétricas, verifica-se que as misturas contendo AMR possuem mais água livre que a mistura de referência. Além disso, as argamassas em que o AMR passou pelo processo de présaturação apresentaram teor de água livre superior ao das misturas sem a compensação. Com relação ao parâmetro $\mathrm{RCH}$, nota-se que, independentemente da pré-saturação, o AMR não reagiu, pois a quantidade de água quimicamente combinada relativa ao hidróxido de cálcio praticamente não variou. Isso indica que não há atividade pozolânica da fração fina do RCD utilizado nesta pesquisa.

A presença do AMR promoveu o aumento dos parâmetros $\mathrm{TH}$ e $\mathrm{OH}$, indicando um incremento na água quimicamente combinada relativo aos hidratos (exceto hidróxido de cálcio). Para o teor de $50 \%$ de AMR pré-saturados observa-se maior quantidade de água combinada (seguida pela mistura com $25 \%$ de AMR também com compensação). Para as misturas sem compensação, houve apenas uma pequena diferença da quantidade de água combinada em relação aos teores de substituição. No entanto, ambas as misturas apresentam mais água combinada que a mistura de referência. $\mathrm{O}$ aumento dos parâmetros $\mathrm{TH} / \mathrm{OH}$ sem haver reatividade pozolânica pode indicar que o AMR pode contribuir como pontos para nucleação e dispersão das partículas do cimento, favorecendo a hidratação.

Como mostrado na micrografia da Figura 3, o AMR possui elevada superfície específica e superfície rugosa. Assim, quando a pasta de cimento entra em contato com o AMR, parte da pasta impregna os poros, e com o avanço da hidratação e o consequente endurecimento da matriz, parte da água absorvida pelos agregados pode retornar à matriz, gerando pontos (ou núcleos) de hidratação retardados e hidratos desconectados. Dessa forma, a presença do AMR gera mais hidratos, porém, provavelmente, desconectados e com maior volume de poros.

\section{Resistência à compressão axial}

A Figura 6(a), 6(b) e 6(c) apresenta a relação entre a resistência à compressão axial das argamassas em função da idade, para o teor de $25 \%$, enquanto a Figura 7(a), 7(b) e 7(c) apresenta a relação entre a resistência à compressão axial das argamassas em função da idade, para o teor de $50 \%$ de substituição de areia natural por AR.

Os resultados obtidos indicam que a presença do agregado miúdo reciclado promoveu redução na resistência à compressão das argamassas de referência para todas as idades estudadas, independentemente do tratamento dado ao agregado reciclado, para ambos os teores de substituição.

Em relação às misturas sem compensação, como não houve variação do teor de água acrescentado à mistura, a redução da resistência foi ocasionada pela presença da água livre (comprovada nos ensaios termogravimétricos), que deve ter fragilizado a zona de transição. Teoricamente, quando não é feita a compensação, espera-se maior absorção e menor relação água/cimento, com o consequente aumento da resistência, devido à elevada porosidade do agregado. Porém, esse efeito não foi observado nas misturas avaliadas. A presença de água livre associados a núcleos de hidratação retardados e hidratos desconectados pode ter gerado maior volume de poros desconectados, contribuindo para a redução da resistência à compressão.

Verifica-se que o procedimento de compensação de água promove redução maior na resistência à compressão das misturas independentemente do teor e em todas as idades. Isso indica que o processo de pré-saturação, mesmo gerando quantidade maior de água quimicamente combinada em relação aos hidratos, gera maior impacto na redução da resistência à compressão axial, porque a água compensada pode não ficar retida no agregado reciclado, sendo transferida para a pasta, aumentando a relação a/c real em volta do agregado e, consequentemente, contribuindo para a formação de uma estrutura de poros maiores. Esse comportamento ocorre também nas misturas com relações a/c $=0,5$ e 0,6 . Nota-se que o processo de compensação influenciou de forma mais significativa as misturas com o teor de $25 \%$ nas idades iniciais, em geral, quando comparado com misturas de teor de $50 \%$. 
Figura 6 - (a) Resistência à compressão axial versus idade para o teor de AMR de $25 \%$ e a/c = 0,4; (b) Resistência à compressão axial versus idade para o teor de AMR de $25 \%$ e $a / c=0,5$; e (c) Resistência à compressão axial versus idade para o teor de AMR $25 \%$ e $a / c=0,6$

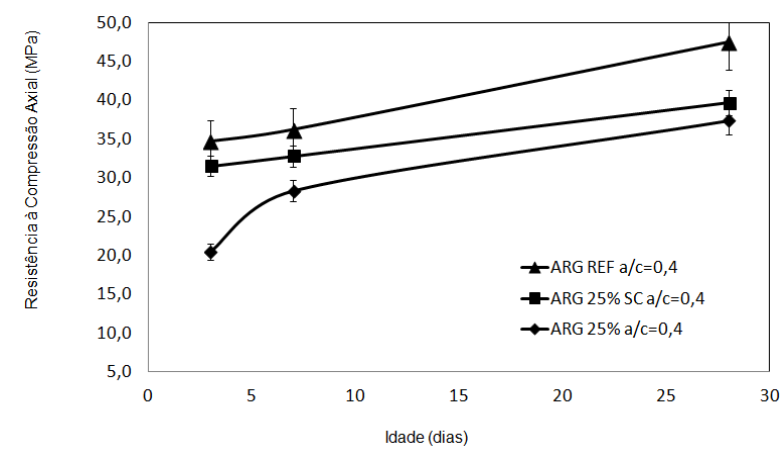

(a)

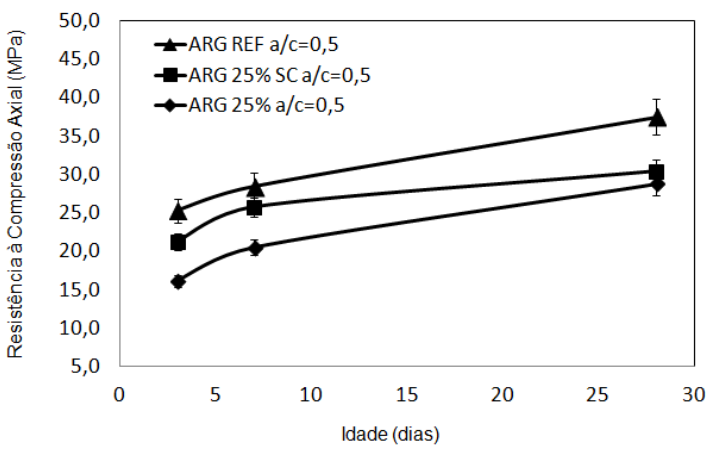

(b)

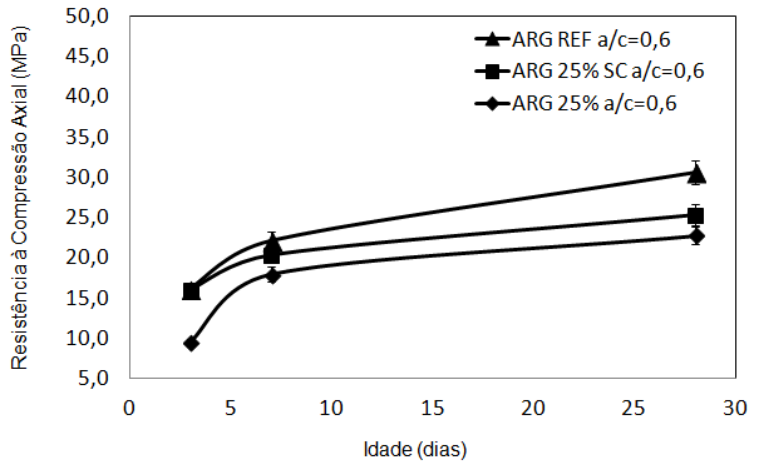

(c)

Figura 7 - (a) Resistência à compressão axial versus idade para o teor de AMR de $50 \%$ e a/c = 0,4; (b) Resistência à compressão axial versus idade para o teor de AMR de $50 \%$ e $a / c=0,5$; e (c) Resistência à compressão axial versus idade para o teor de AMR de $50 \%$ e a/c $=0,6$

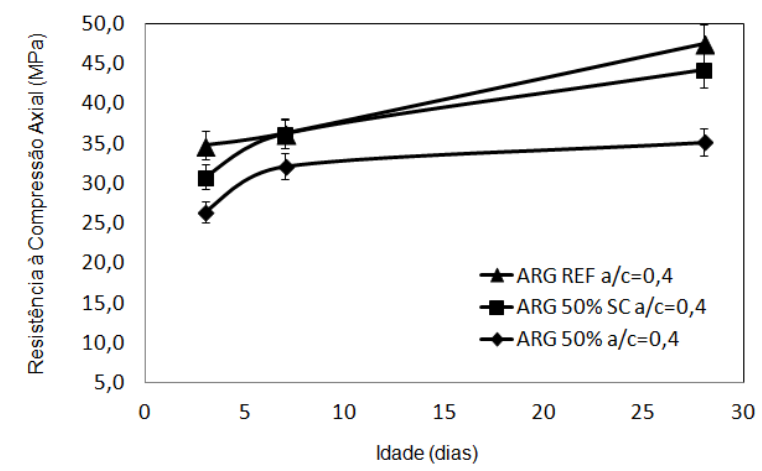

(a)

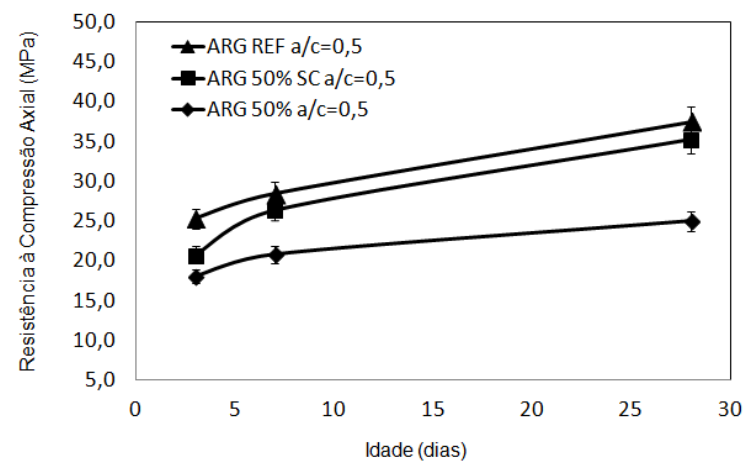

(b)

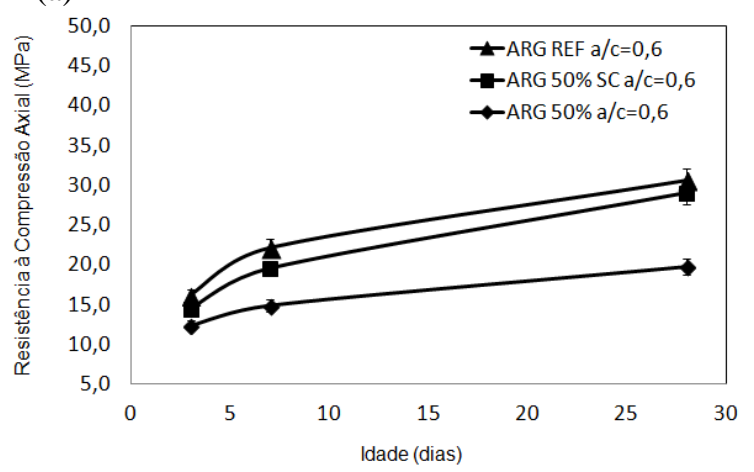

(c) 
Para as misturas sem compensação, nota-se que o impacto nas misturas com teor de $25 \%$ para a idade de 28 dias foi significativo, apresentando pouca diferença em relação ao processo de compensação nessa mesma idade, porém se mostrou ainda menor em relação ao impacto negativo causado no processo de compensação. Já para as misturas com teor de $50 \%$ ocorreu o contrário: o processo de compensação gerou grande impacto na idade de 28 dias, diminuindo bastante este impacto quando não se pratica a compensação para essa mesma idade.

A partir da análise de variância da resistência à compressão das misturas avaliadas para um nível de significância de $\alpha^{*}=0,05$, verifica-se que existe diferença significativa entre as médias quando se variam as relações água/cimento $(0,4$, $0,5,0,6)$, e também entre as médias dos métodos de preparo do agregado reciclado (com compensação e sem compensação). Isso significa que compensar ou não compensar a água influencia a resistência à compressão das argamassas.

Para o teor de agregado reciclado empregado nas argamassas $(0 \%, 25 \%$ e $50 \%)$ também existe diferença significativa entre as médias, ou seja, utilizar agregado reciclado promove redução na resistência à compressão axial das argamassas, independentemente do teor de substituição, método de tratamento e idade.

\section{Conclusões}

Este trabalho é uma contribuição para os estudos de dosagem de argamassas com agregados reciclados. A partir dos resultados obtidos é possível entender melhor o funcionamento da matriz cimentícea, o que possibilitará, na prática, uma utilização mais segura e correta dos agregados reciclados.

Constatou-se que a pré-saturação influencia as propriedades das argamassas nos estados fresco e endurecido.

Os valores de viscosidade para as argamassas com areia reciclada foram superiores aos das argamassas de referência, principalmente para fatores água/cimento baixos, como é o caso de a/c $=0,4$. Esse fato pode ser atribuído à inserção do agregado reciclado, que apresenta contornos irregulares e textura mais áspera, o que aumenta a tensão de cisalhamento entre os grãos, dificultando o escoamento entre eles.

A análise termogravimétrica mostrou que a saturação do AMR promove misturas com mais água livre e maior quantidade de água quimicamente combinada relativa aos hidratos, exceto hidróxido de cálcio.

A presença do agregado miúdo reciclado promoveu redução na resistência à compressão das argamassas em todas as idades, independentemente do tratamento dado ao agregado reciclado (présaturação ou não), para ambos os teores de substituição. Verifica-se que a pré-saturação promove redução mais significativa na resistência à compressão das misturas, independentemente do teor, em todas as idades e para todas as relações a/c. O processo de pré-saturação gera maior impacto na redução da resistência à compressão axial porque a água compensada pode não ficar retida no agregado reciclado, sendo transferida para a pasta, aumentando a relação a/c real em volta do agregado e, consequentemente, contribuindo para a formação de uma estrutura de poros maiores.

\section{Referências}

ÂNGULO, S. C. Caracterização de Agregado de Resíduos de Construção e Demolição Reciclados e a Influencia de suas Características no Comportamento de Concretos. 149 f.São Paulo, 2005. Tese (Doutorado em Engenharia Civil) Escola Politécnica, Universidade de São Paulo, São Paulo, 2005.

\section{ASSOCIAÇÃO BRASILEIRA DE NORMAS}

TÉCNICAS. NBR NM 45: determinação da massa unitária e do volume de vazios. Rio de Janeiro, 2006.

\section{ASSOCIAÇÃO BRASILEIRA DE NORMAS TÉCNICAS. NBR NM 46: agregados:} determinação do material fino que passa através da peneira $75 \mu \mathrm{m}$, por lavagem. Rio de Janeiro, 2003a.

ASSOCIAÇÃO BRASILEIRA DE NORMAS TÉCNICAS. NBR NM 52: agregado miúdo: determinação da massa específica e massa específica aparente. Rio de Janeiro, 2009b.

\section{ASSOCIAÇÃO BRASILEIRA DE NORMAS} TÉCNICAS. NBR NM 248: agregados: determinação da composição granulométrica. Rio de Janeiro, 2003b.

\section{ASSOCIAÇÃO BRASILEIRA DE NORMAS}

TÉCNICAS. NBR 7211: agregados para concreto: especificação. Rio de Janeiro, 2009a.

\section{ASSOCIAÇÃO BRASILEIRA DE NORMAS}

TÉCNICAS. NBR 7215: cimento Portland:

determinação da resistência à compressão. Rio de Janeiro, 1996. 
BARRA, M. Estudio de la Durabilidad del Hormigón de Árido Reciclado en su Aplicación Como Hormigón Armado. 131 f. Barcelona, 1996. Tese (Doutorado em Engenharia da Construção) - Escola Técnica Superior d'Énginyers de Camin, Canal i Ports, Universitat Politécnica de la Catalunya, Barcelona, 1996.

CARRIJO, P. M. Análise da Influência da Massa Específica de Agregados Graúdos Provenientes de Resíduos de Construção e Demolição no Desempenho Mecânico do Concreto. 129 f. São Paulo, 2005. Dissertação (Mestrado em Engenharia Civil) - Escola Politécnica, Universidade de São Paulo, São Paulo, 2005.

DWECK, J. et al. Thermogravimetry on Calcined Mass Basis: hydrated cement phases and pozzolanic activity quantitative analysis. Journal of Thermal Analysis and Calorimetry, v. 97, n. 1, p. 85-89, 2009.

ETXEBERRIA, M. et al. Influence of Amount of Recycled Coarse Aggregates and Production Process and Properties of Recycled Aggregate Concrete. Cement and Concrete Research, v. 37, n. 5, p. 735-742, 2007.

EVANGELISTA, L.; BRITO, J. Durability Performance of Concrete Made With Fine Recycled Concrete Aggregates. Cement and Concrete Composites, v. 32, n. 1, p. 9-14, 2010.

FERREIRA, L., BRITO, J.; BARRA, M. Influence of the Pre-Saturation of Recycled Coarse Concrete Aggregates on Concrete Properties. Magazine of Concrete Research, v. 63, n. 8, p. 617-627, 2011.

GÓMEZ-SOBERÓN, J. Porosity of Recycled Concrete With Substitution of Recycled Concrete Aggregate: an experimental study. Cement and Concrete Research, v. 32, n. 8, p. 1301-1311, 2002.

GONÇALVES, R. D. C. Agregados Reciclados de Resíduos de Concretos: um novo material para dosagens estruturais. 148 f. São Carlos, 2001. Dissertação (Mestrado em Engenharia Civil) Escola de Engenharia, Universidade de São Paulo, São Carlos, 2001.

GONÇALVES, J. P. et al. Estudo da Hidratação de Pastas de Cimento Portland Contendo Resíduo Cerâmico por Meio de Análise Térmica.

Ambiente Construído, Porto Alegre, v. 6, n. 4, p. 83-94, out./dez. 2006.
LEITE, M. B. Avaliação de Propriedades Mecânicas de Concretos Produzidos com Agregados Reciclados de Resíduos de Construção e Demolição. 270 f. Porto Alegre, 2001. Tese (Doutorado em Engenharia Civil) Escola de Engenharia, Universidade Federal do Rio Grande do Sul, Porto Alegre, 2001.

LEVY, S. M. Contribuição ao Estudo da Durabilidade de Concretos Produzidos com Resíduos de Concreto e Alvenaria. 208 f. São Paulo, 2001. Tese (Doutorado em Engenharia Civil) - Escola Politécnica, Universidade de São Paulo, São Paulo, 2001.

LIMA, J. A. R. Proposição de Diretrizes Para Produção e Normalização de Resíduo de Construção Reciclado e de suas Aplicações em Argamassas e Concretos. 204 f. São Carlos, 1999. Dissertação (Mestrado em Engenharia Civil) - Escola de Engenharia, Universidade de São Paulo, São Carlos, 1999.

MACHADO JÚNIOR, E. F.; AGNESINI, M. V. C.; BALLISTA, L. P. Dosagem de Microconcretos Estruturais Leves com Agregados Reciclados de Construção e Demolição: estudo de caso. In: ENCONTRO NACIONAL DE TECNOLOGIA DO AMBIENTE CONSTRUÍDO, 8., Salvador, 2000. Anais... Salvador, 2000.

MALTA, J. O. Dosagem de Concretos Produzidos com Agregado Miúdo Reciclado de Resíduo de Construção e Demolição. 192 f. Salvador, 2012. Dissertação (Mestrado em Engenharia Ambiental e Urbana) - Escola Politécnica, Universidade Federal da Bahia, Salvador, 2012.

PEDROZO, R. F. E. Influencia da Substituição do Agregado Miúdo Natural por Agregado Reciclado Fino em Propriedades de Argamassas e Concretos. 178 f. Florianópolis, 2008. Dissertação (Mestrado em Engenharia Civil) Programa de Pós-Graduação em Engenharia Civil, Universidade Federal de Santa Catarina, Florianópolis, 2008.

REIS, C. N. Influência da Utilização de Agregado Miúdo de RCD na Aderência AçoConcreto Reciclado. 170 f. Feira de Santana, 2009. Dissertação (Mestrado em Engenharia Civil e Ambiental) - Universidade Estadual de Feira de Santana, Feira de Santana, 2009.

TAYLOR, H. F. W. Cement Chemistry. $2^{\text {nd }}$. ed. London: Thomas Telford, 1997. 459 p. 
VASQUEZ, E. et al. Utilización de Árido

Reciclado Para la Fabricación de Hormigón

Estructural. Comisión 2, Grupo de Trabajo 2/5 -

Hormigon Reciclado, Monografia M-11, ACHE,

Madrid. 2006.

VIEIRA, G. L. Estudo do Processo de Corrosão

Sob a Ação de Íons Cloreto em Concretos

Obtidos a Partir de Agregados Reciclados de

Resíduos de Construção e Demolição. 150 f.

Porto Alegre, 2003. Dissertação (Mestrado em

Engenharia Civil) - Escola de Engenharia,

Universidade Federal do Rio Grande do Sul, Porto

Alegre, 2003.
ULSEN, C. et al. Production of Recycled Sand from Construction and Demolition Waste.

Construction Building Materials, v. 40, n. 3, p. 1168-1173, 2013.

\section{Agradecimentos}

Os autores agradecem aos órgãos que fomentaram este trabalho (Fapesb, Capes e CNPq).

\section{Juliana Oliveira Malta}

Diretoria de Planejamento de Obras e Projetos | Instituto Federal de Educação, Ciência e Tecnologia de Sergipe | Avenida

Desembargador Maynard, 549, Suíssa | Aracaju - SE - Brasil | CEP 49052-210 | Tel.: (79) 3711-3186 | E-mail: jumalta@hotmail.com

\section{Vanessa Silva Silveira}

Departamento de Ciência e Tecnologia dos Materiais, Escola Politécnica | Universidade Federal da Bahia | Rua Aristides Novis, 02, DCTM, Federação | Salvador - BA - Brasil | CEP 40210-910 | Tel.: (71) 3283-9853 | Email: vanessa.dctm@gmail.com

\section{Jardel Pereira Gonçalves}

Departamento de Ciência e Tecnologia dos Materiais, Escola Politécnica | Universidade Federal da Bahia | Tel.: (71) 3283-9485 |

Email: jardelpg@ufba.br

\section{Romildo Dias Toledo Filho}

Programa de Engenharia Civil | Universidade Federal do Rio de Janeiro | Cidade Universitária, CT, Bloco B | Itha do Fundão | Caixa Postal 68506 | Rio de Janeiro - RJ - Brasil | CEP 21945-970 | Tel.: (21) 2562-8479 | Email: toledo@coc.ufrj.br

Revista Ambiente Construído

Associação Nacional de Tecnologia do Ambiente Construído

Av. Osvaldo Aranha, $99-3^{\circ}$ andar, Centro

Porto Alegre - RS - Brasil

$$
\text { CEP } 90035-190
$$

Telefone: +55 (51) 3308-4084

Fax: +55 (51) 3308-4054

www.seer.ufrgs.br/ambienteconstruido

E-mail: ambienteconstruido@ufrgs.br 